\title{
Integrating Teaching Method to Improve the Effects of Digital Audio and Video Post-production Teaching
}

\author{
Rong-Wang Hsu
}

\begin{abstract}
Digital audio and video post-production is a computer course in multimedia and its content usually adapt to the promotion of technology. The teaching methods used in class must be diverse including pre-class questionnaire, peer-assistant learning methods, digital learning platforms, and equipment for recording studios. Through the course, students can accumulate professional works and obtain international professional certification of digital audio and video, with which they can add points in internship interviews, get internship opportunities, and probe for post-graduation career. After-course questionnaire will be used to analyze student learning outcomes and used as basis for further adjustment of the course. This research report is for digital post-production courses, which is the course I have taught for many years. Now I have improved the traditional teaching methods in the past, which include the use of the multi-methods mentioned in the literature and the use of teaching equipment equipped with hardware and software. Not only has it improved the effectiveness of student learning, but it has also improved students' professional skills. From the final statistical questionnaire, it seems that students also highly praise my teaching method.
\end{abstract}

Index Terms-Digital audio and video post-production, learning process, learning effectiveness.

\section{INTRODUCTION}

Digital audio and video post-production was categorized as one computer course of multimedia. The course contents were adjusted according to use of new technology no matter how software was employed, version was updated, or creative works were applied. Therefore, teaching methods or philosophy must meet teaching objectives instead of traditional teaching methods which was not flexible and unchanged. In order to achieve teaching objective, teachers must constantly enrich their profession, participate in activities of academic social group, and adjust course contents and teaching philosophy. Pre-course questionnaires must be conducted before first class in order to understand the learning history of students. Then, contents of teaching material unit or teaching hours may be increased or decreased so as to bring to students the most suitable course contents and teaching methods. Professional software and hardware equipment must be employed in teaching process and teaching environment must be constructed using digital

Manuscript received November 13, 2019; revised February 13, 2020

Rong-Wang Hsu is with Department of Applied Digital Media, Wu Feng University, Taiwan (e-mail: ronger@wfu.edu.tw). teaching platform in order for students to learn under a good environment.

In digital learning platform, messaging function of billboard may be used to remind students to pay attention to the learning notes. Discussion forum may be created to discuss course contents or answer student questions. According to course progress, weekly course and teaching material files may be uploaded for students to do the after-class practicing. Test bank may be added for students to view their learning outcomes. The function of assignment due may be added for students to upload homework, for teacher to understand what extent students learn the unit contents and make the assessment, for students to know their learning outcomes, for teacher to view the last login time to understand and grasp the participation situation of the course at any time through the generated learning-related reports and data in the learning process.

Collaborating with each other in learning was encouraged. The seats may be arranged appropriately based on the pre-course questionnaires, in which strong students may be arranged next to the students with weak learning ability to conduct peer-assist learning and achieve $1+1>2$ learning outcomes. After-class tutoring mechanism may be created for students to obtain direct assistance from teacher after class whenever and whoever necessary so as to promote learning motives. Course of digital audio and video post-production may be arranged in pairs with international certificate tutoring in order to pass and obtain the certificate before the end of course. Diverse assessment of student learning outcomes may be adopted including the level of participation, contents and number of assignment due, international certification, peer-assist learning, and digital learning platform-related reports so as to evaluate student learning outcomes and achieve and fulfill the teaching objectives. Strong students may be encouraged to integrate course contents with creative idea using after-class hours so as to extend creative works, which can successfully pass the interview for off campus practice, practice earlier in industry, and accumulate practical experience in order to seamlessly align with employment after graduation.

Based on the data analysis of post-course questionnaires [1], [2] and assessment for the course, student learning outcomes presented very outstanding results in terms of obtaining of professional skills, numbers of professional certification, performance of club activities, improvement of teaching material, and employment status after graduation in addition to the assessment for the course, which greatly promoted self-learning achievement. The teaching concept establishment and practice flow chart is shown in Fig. 1 below. 


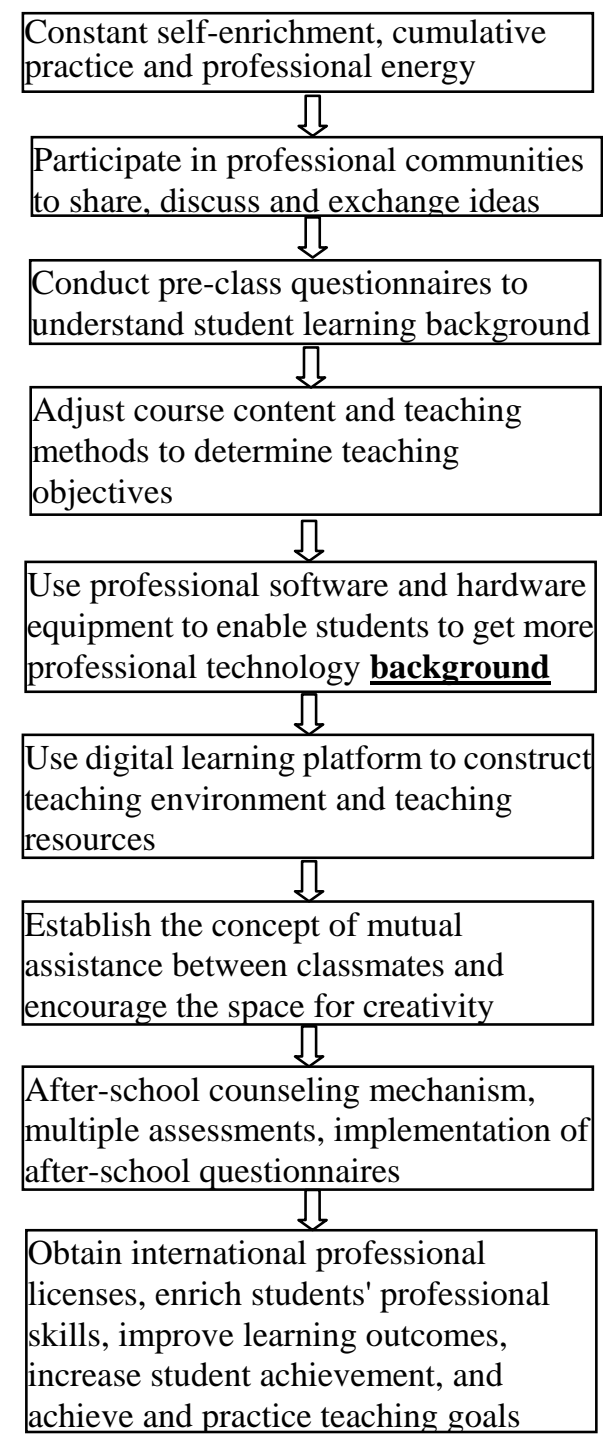

Fig. 1. The teaching concept establishment and practice flow chart.

\section{LITERATURE REVIEW}

Scholar's comments concerning on promotion of student learning outcomes, increase of student learning achievements, achievement and fulfillment of teaching objectives, enhancement of teaching professional abilities, participation of professional social group, use of network learning platform, seat arrangement for peer-assist learning, and international professional certification are elucidated as follows.

\section{A. Promoting Professional Ability of Instructor}

Teachers must constantly self-grow, enrich expertise, and promote professionalism which were fundamental to promote learning of students [3]. Scholar [4] thought teachers must be familiar with course contents of teaching material and student ability index and also transform into a teaching goal that meets the student ability so as to complete adaptive teaching plan. Differentiated teaching strategies were employed in teaching process to promote student learning outcomes for different students. Diverse assessments were employed after course to diagnose learning gap and improve teaching strategies to achieve teaching objectives. Scholars [5] thought teaching efficacy of teachers consisted of teaching contents, teaching skills, interaction of teacher and students, student learning performance, and teaching reflection. Scholars [6] thought teaching efficacy of teachers consisted of self-efficacy belief, teaching plan, teaching material strategies, teaching strategies, teaching assessment, and teaching atmosphere. Teachers must cooperate with colleague and professional social groups to increase experience sharing opportunities in addition to teacher's own professional skills improvement.

\section{B. Joining Social media Group of Expertise and Experience}

Scholars [7]-[9] found in her research that most teachers could constantly self-learn after joining professional social groups and also construct more sophisticated professional knowledge through experience transfer of community members.

Scholar [10] indicated that sharing and discussion among teachers in professional social groups could stimulate reflection of teaching contents or professional abilities. Teachers professional abilities could constantly grow and innovate through professional dialog and pay more attention to student learning situations. Members of teacher professional learning group made teaching files, promoted teachers' professional growth, improved student learning, and improved teaching efficacy [10]-[13].

Scholar [14] pointed out that professional learning social group focused learning on specific professional domain so as to promote professional development and growth and thus improve student learning performance. The purpose of teacher professional learning social group was to improve student learning outcomes and focused all resources on student learning so as to promote student learning outcomes [15].

\section{Employing Network Learning Platform}

Using network technology for assisted learning has become a trend today. The learning process was completely online. Scholars [16] mentioned in his research that digital learning is important to promote the current level of teaching technology. Through the reasonable integration of current teaching techniques could effectively promote the teaching quality of teachers.

The digital learning system was a learner-centered and flexible learning method among many learning methods [17], [18]. Scholars [19] thought digital teaching platform was to use the advantages of digital technology to provide a space for information exchange on the Internet. Using the learning platform to assist in teaching, in addition to promoting the quality of teaching, it could also expand the space and scope of learning, thereby enhancing the teaching effect [20]-[24].

\section{Peer-assistant Learning}

Peer learning tutoring was a one-to-one teaching mode for low-achieving students by well-trained students under the guidance of teachers [25], [26]. Less experienced students was assisted by more experienced students in the peer-to-peer system [27].

\section{E. International Certification}

In recent years, when enterprises selected talents, the university diploma has gradually lost its discriminating 
power, and it was bound to require other auxiliary terms as a criterion for judging talents [28]. Moreover, nowadays, the colleges and universities offered a wide range of professional courses, and students must have basic professional skills before they could cope with the future work environment [29]. The recognition of knowledge mostly lay in the recognition of the professional certifications obtained, meanwhile, it would also have better positions and income for future work. Generally speaking, the so-called specialty could be expressed as an intention or purpose, moreover, it had the meaning of personal claiming special skill, knowledge and technology [30].

Professional certification represented a symbol of professional competence whether or not it had legal effect [31]. Scholars [32] thought professional certification could effectively visualize the individual's professionalism and provided a certain degree of reliability and validity on behalf of individuals in performing a task. The significance of the current professional certification had become an individual's employment and competition in the workplace.

Scholars [33], [34] also proposed a treatise that the certifications could help the connection between industry and education, emphasizing that the employer could quickly see whether the job seeker had the required functions by professional certification. On the other hand, job seekers could take up the job immediately or quickly after they were admitted, without the need for the employer to spend additional training costs and time. A complete certification system undoubtedly helped to correct the Taiwan diploma orientation and the phenomenon of cramming education, thereby helping to promote competitiveness.

Therefore, the above scholars had pointed out that participation in the study and professional social groups could promote the professionalism of teachers, coupled with the use of network platforms, peer-assist learning between students, and counseling students in obtaining professional international certifications after course. It could effectively improve student learning and thus promote students learning efficiency.

\section{RESEARCH METHOD}

There were 54 class hours in 18 weeks with 3 lessons each time and every week for Digital Audio and Video Post-production which covered two parts: sound effect and post-production editing. Six to 12 hours were required for evaluation of pre-learning history in the former. Some students had experience in using PowerDirector for post-production and were familiar with the special effect and transition in editing. So, 33 to 36 hours were required for consideration of pre-learning background of similar courses taken and software used in the latter.

Besides, the design of the course included SSE (Silicon Stone Education) international certification of Premiere. Six hours were required for interpretation and simulation test so that the students could understand test rules, question type, and simulation test. Three hours were required for the formal test. The teaching was in a professional computer room equipped with Adobe software, Premiere, After Effect, and Mixcraft.
For effective teaching practical skills of the course and fulfillment of teaching philosophy, I proposed some improved methods and skills as follows: self-adjust teaching methods by accumulation of experience; participate in teaching club on campus to share, discuss, and exchange of opinions with colleague and industry teacher; understand student learning history by pre-questionnaire to tailor course content so as to determine student learning objectives; obtain more professional techniques by using professional hardware and software equipment and resource; construct student learning environment by using digital learning; establish peer-assist learning and encourage student to unleash creative space; carry out after-class tutoring and diverse assessment mechanism to promote student learning outcomes and obtain more solid techniques. These methods and skills are elucidated in detail as follows.

\section{A. Adapting Teaching Mode}

In traditional teaching methods, one or two textbooks was selected from similar topics for the class based on different book catalogs and popularity from the publishers and chapters in textbook were followed in teaching. CD attached to the textbook was the teaching material. After some adjustment and revise of the course content in those years, textbooks ended up not mandatory because of its limited learning contents. Therefore, it was very important to spend time to gather various course-related teaching contents including interpretation examples in general computer books, production skills examples, homework practices, and advanced example extensions. Some good works from network or Face Book and teaching paradigm from YouTube were assimilated into course units. Some professionals posted their post-production techniques on YouTube to be shared or subscribed. These good teaching exemplifications acted as an inspiration in addition to the creatives of students or change of parameters turned into my learning to harvest.

My teaching experience and many classic examples in my teaching materials has accumulated in recent years. New technologies were added. For example, film tension was presented by time-lapse photography technique while assimilated into MV. Visual sense of the video was Highlighted while animation effect was increased by plug-in technique. Old software version was also adjusted. For example, producing and exporting closed caption videos using Photoshop instead of using plug-in caption. Some good examples were gathered in the preparation of the teaching materials. For example, the effect of translation transition which is indispensable in film change process often appears in the technique of video or movies as demonstrated in Fig. 2.

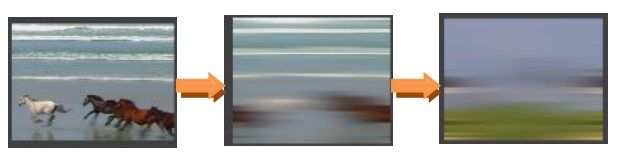

Fig. 2. Effect of translation transition.

Students came to class to gain professional skills and were encouraged to unleash creativity in the course of digital editing and post-production. The classic examples could be modified or extended to accumulate works so as to have more profound professional technology. Besides, the adjustment of 
self-mind was important. Due to the effect of low birth rate in recent years, the percentage of students from vulnerable family or of decreased student learning ability increased. Therefore, teaching attitude and methods were adjusted and modified instead of traditional dull mode. Nowadays, teaching methods were effective only by encouraging students instead of reproaching, promoting student's respect to teachers with love and tolerance, teaching students to gain knowledge with professional skills.

\section{B. Joining Group of Department}

Joining digital entertainment practice teaching group and digital design group to share, discuss, and exchange of opinions with colleagues or industry teachers as indicated in Fig. 3, in which I also heard, learned, and felt the experiences sharing and exchange of opinions from industry experts and senior teachers. Understand the criteria and characteristic of professional human resources so as to remind the students or assimilate into course unit while teaching. For example, most post-production companies recruited for new team members harnessed with clear critical thinking logic, more creative ideas, innovation and personality, telling stories by using images, and good at communication traits.

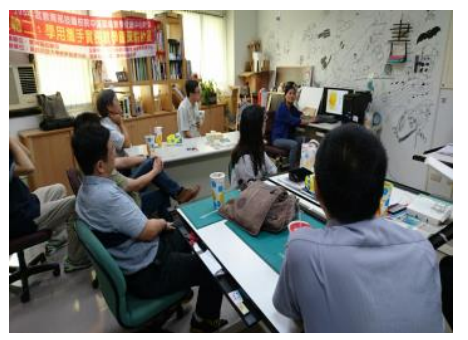

Fig. 3. Speech on industry dynamics by industry teacher - A group activity.

Senior teachers not only published the most suitable teaching material in professional domain to promote teaching quality, give suggestions to students to use more course material on digital learning network or dialog platform but also discussed the classroom performance of some students or gave students some suggestions and assistance. Professional social media groups have given positive energy in recent years, in which I obtained more teaching resources and was more determined to fulfill my teaching philosophy.

\section{Exercising Pre-course Questionnaire}

Course contents were adjusted to meet teaching objectives according to the student learning background investigated by pre-course questionnaires, which also served as important reference of student learning methods in situational learning and adjustment of teaching material. The student learning outcomes could be grasped based on the feedbacks from students investigated by after-course questionnaires, which also served as reference of improvements of course units and teaching methods afterwards.

The basic profession of students couldn't be grasped and the course contents wouldn't be adjusted if the student learning history wasn't identified, which caused students big trouble in learning because the teaching was based on obsolete teaching materials. In earlier years, the student learning backgrounds were roughly inquired in class without pre-course questionnaires. It often ended up with a noisy and careless voice because it wasn't easy to hear inner voice of students in Taiwan. It resulted in feedbacks of error messages without substantial understanding and dilemma without knowing where the problems lay. Moreover, it resulted in low learning ability and finally affected performance of professional skills.

I realized where the most basic problem was after analyzing the student learning situation after course. Therefore, pre-course questionnaires were added to grasp clearly the learning history at any time in term of course teaching material and in teaching for students to obtain the biggest gain. Thus, in recent years, pre-course questionnaires were conducted at first class, which included what was learned before, what assistance from teacher was expected, and what was expected after the course so as to give situational learning and adjust course contents and homework for students to obtain most and greatest benefit and for teachers to fulfill teaching objectives.

The introduction and implementation of Mixcraft aiming at the use of material library, the elucidation of speed, section, and tabs were added to the course contents if students were not familiar with sound effect unit or lack of understanding of the sound.

In earlier years, due to lack of teaching experience, learning background was often neglected and learning foundation was taken for granted or learned but just forgot. Maybe many students also thought the same way but the result was actually not. Under such cognition, it resulted in obstacle of course learning, decrease of student learning motives, and lower of student learning outcomes. Therefore, in recent years, pre-course questionnaires were conducted to understand the learning background which served as the base for adjustment of deepness of course contents or increase or decrease of course contents unit. For example, for the course of digital audio and video post-production, complete introduction of sound effect unit was necessarily added to the primary level students who didn't take the course - digital music foundation or pass the international certification of Mixcraft Level 1- Level 2. Other students who took the course might create works by utilizing the files in material library.

Students who were familiar with beat, and high and low music spectrum if they took the course of digital music foundation might employ directly the instruments in material library to create music synthesis. Comparative introduction and advantages and disadvantages analysis were added to the course to increase understanding of post-production software if students were familiar with film post-production and software such as PowerDirector, Movie-Maker, etc.

\section{Using Professional Classroom}

Students obtained more professional skills by using the software and hardware equipment and resources. In earlier computer courses, software as teaching tool required by the course was installed in the computers in professional classroom. Most teachers including me conducted course teaching process only in the professional classroom the whole semester. In recent years, personal teaching resources were constantly adjusted to advance professional skills and meet more suitable requirements by industry. Therefore, the 
equipment in recording room was also employed for sound effect course units which was also an important element of post-production, in addition to post processing. The whole picture of the film couldn't be fully presented without good radio, mix, or dubbing, which helped to create independent work which was also mandatory of the course.

\section{E. Peer-assistant Learning}

Good students could be regarded as small teachers of peer-assist learning to help their peers learn, who, in another hand, could also review their learning material so as to further create creative space. Good classmates unleash their creativity to add composing mix from different material library, meanwhile, classmates with slower learning could also followed up with the progress of the class to achieve class requirement with the help of peer-assist learning. Therefore, seat adjustment was definitely necessary because of both paying attention to learning progress in teaching process whenever necessary and avoiding delay by classmates with slower learning. However, teaching rhythm had to be adjusted for students being able to digest and absorb if the learning unit seemed difficult for even good classmates.

\section{F. Employing Digital Learning Platform}

Students had better teaching-assist learning environment constructed by digital learning platform in which teachers could add announcement column and discussion area for their teaching needs, post teaching material files and test bank for students to download according to weekly course progress for autonomous learning or use of remedial teaching, and viewed the last login time and learning-related reports so as for teachers to grasp the learning situation participated by students at all times. Students with slower learning could go to specific week to review the course contents. Students absent from class could find their available time after class to do self-learning.

In digital learning platform, test type and limited date and time of test could be constructed for students to complete and upload for course assessments in which homework for students could be evaluated and displayed for students to understand their learning outcomes. Teachers could discuss the homework for students to know the requirements of homework and share good students' works in class. Besides, the last login time to the course, not chaos of information, could be used by teachers to remind not logged in for a long time, passive students, grasp students' learning situation, and give assistance in time if needed so as to promote learning motives.

Teachers could understand student learning outcomes based on course-related reports presented by the digital learning platform including course participation and activities report. Generated reports by digital learning platform could also be a resource of course requirements. Teaching activities and resources could be added according to the course requirements to help the establishment and use of the course. Added teaching activities included homework for students to upload their homework by due date and for teachers to assess and discuss homework with students, questionnaires, test banks, chats, and discussion rooms which could be opened for any topic in course processing for students to participate in.

\section{G. After-class Tutoring and Diverse Assessment}

After-class tutoring was brought into practice for the classmates with slower learning to strengthen the learning by digital learning platform or by teacher's appointment. After-class tutoring by teacher's appointment could also be provided for good students to enhance professional skills and discuss creative usage, which all helped to promote student learning motives. Of course, I was incumbent to give due assistance to students whenever necessary.

In the diverse assessment of course, it had a big change compared to traditional exam held and homework due. Most students were afraid of exam which was hard to see the student learning outcomes and usually caused bad learning methods in class. It was also difficult to assess student learning outcomes based only on uploaded homework which might be done by others or plagiarized by students, which way resulted in incorrect assessment. So, diverse assessment was probably the best way to assess student learning outcomes including rate of attendance, learning vigor in class, practice assignment in class, result of peer-assist, creative works, international certification, asking questions in class, and after-class exercises which were elucidated at first class for students to fully understand and come up with the best learning attitude in class.

Rate of attendance meant participation of course. The higher rate of attendance, the more course contents students could learn, thus, a factor of assessments. Students with weak learning ability could obtain help from peer-assist learning, meanwhile, strong students could strengthen their understanding, which resulted in $1+1>2$ learning outcomes. Students could raise questions immediately if there is any. During the time period of practices, I always paid attention to the practice process of students and helped to resolve the problems or expounded again if necessary. For strong students, I gave them more instructions or opinions of their works so they could unleash more. Besides, the student learning outcomes of sound effect, usage of recording room, familiarity of editing and text processing, achievement rate of assignment in class, number of assignments due, and response to course and learning ability in class were also all factors of assessments so as to promote student learning outcomes without learning burdens.

There was an exam of Adobe Premiere which was employed in class for the course for SSE (Silicon Stone Education) international certification at the end of semester, which was ranked middle-level certification in the department. SSE Adobe Series CC provided six categories of certificates while Adobe Series CS6 provided seven categories of certificates, which obtain affirmative for global competitive strength. Adobe Premiere CS6 Examination Contents consists of eight parts including Transitions, Video composition, Creating dynamic special effects, Designing Subtitles, Operating time, Film color, Project management, Video export and application. So, students had to be very shilled with this application software and integrated all techniques used in different use case in order to pass the test and earn the international certificate. Students had to fully 
understands the contents of every items and attended after-class tutoring to strengthen the practices for interface familiarity, problem solving process, and familiarity and concepts of editing in order for students to promote in professionalism and proficiency.

\section{RESEARCH RESULTS}

I conducted an after-course questionnaire before the end of the course, in which the expectation of course, student learning outcomes, and suggestions for teacher can be used to make an adjustment of teaching material units and assignments in the future and which let me know the advantages and disadvantages of student learning mode so that I can improve in the future, also in which the degree of achievement of teaching objectives can be identified, suggestions of course progress and teaching unit can be used to make an adjustment next time. Even more, other learning mode or internship opportunities such as distance learning, flipped classroom, MOOCs (Massive Open Online Courses), off-campus visit, off-campus internship, etc. can also be evaluated in the future.

\section{A. Course Assessment}

After the implementation of the adjustment of conceptual basis and method in class, continuous update of technique and case, constant update and use of professional equipment, keeping an eye out the questions raised by students in the course, peer-assist learning, diverse assessments, and after-class tutoring, both the acquisition of the course taken and the cultivation of professional skill were obviously progressive. The satisfiability of course was increased year by year, which was positive cycle and positive affirmative from students and which made me work hard to be constantly progressive and adaptive. The course assessment of digital audio and video post-production presented the outcome and response of learning satisfiability. In 2015, the learning satisfiability was 4.2 which was less than campus-wide average satisfiability (4.43). In 2016, it was 4.21 which was also less than campus-wide average satisfiability (4.44.) In 2017 , it was 4.56 which was greater than campus-wide average satisfiability (4.49). In 2018, it was 4.68 which was greater than campus-wide average satisfiability (4.53) as indicated in Table I and Fig. 4.

TABLE I: TEACHER ASSESSMENT OF COURSE (POINTS)

\begin{tabular}{|c|c|c|}
\hline Year & Class Satisfiability & $\begin{array}{c}\text { Campus-wide Average } \\
\text { Satisfiability }\end{array}$ \\
\hline 2015 & 4.2 & 4.43 \\
\hline 2016 & 4.21 & 4.44 \\
\hline 2017 & 4.56 & 4.49 \\
\hline 2018 & 4.68 & 4.53 \\
\hline
\end{tabular}

\section{B. International Certification}

International professional certification Adobe Premiere CS6 certified by SSE was added to the courses of 2017 and 2018. Starting the first semester of 2017 and 2018, Thirty-six students sign up each year and studied hard in addition to my tutoring in class and after class so that the passing rate was $100 \%$ which promoted the student learning outcome and increased the satisfiability of the course. The student learning outcomes was excellent in addition to the increased degree of affirmative of students.

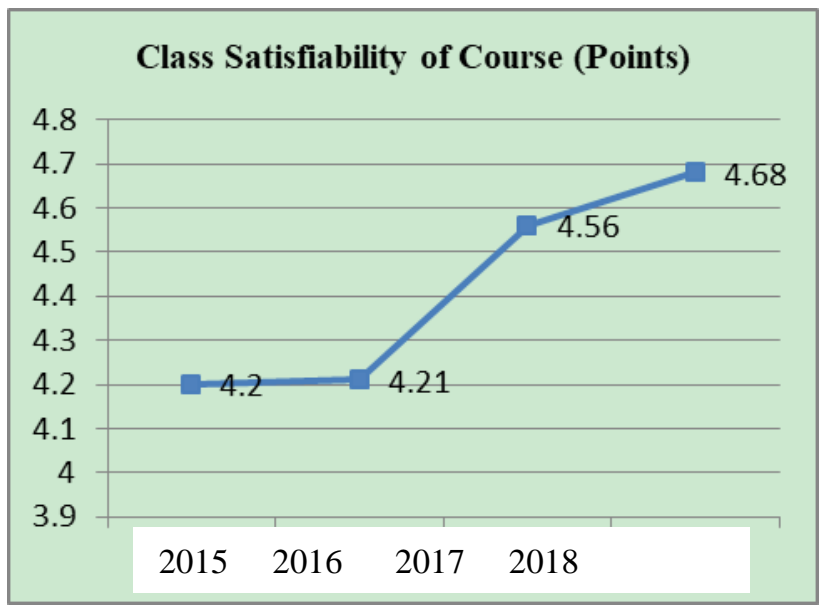

Fig. 4. Teacher assessment of course (points).

\section{Teaching Improvement of Course}

Teaching materials have been constantly adjusted and some innovative modus operandi and skills was added in these years so that my teaching materials won the award "Excellent" in 2018 Teaching Improvement Program, which was believed to affirm the help of learning, as indicated in Table II.

TABLE II: COURSE WORK FROM TEACHING IMPROVEMENT

\begin{tabular}{|c|c|c|c|}
\hline Year & Title & Category & Award \\
\hline \multirow{3}{*}{2018} & Digital Audio & Teaching material, teaching aid & \\
& $\begin{array}{c}\text { and Video } \\
\text { System }\end{array}$ & $\begin{array}{c}\text { - teaching equipment, teaching } \\
\text { aid, teaching-assist material }\end{array}$ & Excellent \\
& Sych & \\
\hline
\end{tabular}

\section{Performance of Guitar Club of Student Society}

Clubs on campus were encouraged and tutored to use the equipment of professional audio room in the moreover, department and students were welcome to use the equipment as well so that they could practice whenever they were available and conduct a rehearsal before their performing. Some students were assigned to assist if there were demands of audio recording on or off campus, which demonstrated the professional essence and attitude of what they have learned in the meanwhile. I gave professional assistance and tutoring to the members of guitar club whenever they conduct a rehearsal or recording so that they could perform well in every activity. Moreover, they performed in off-campus activities such as culture park in Chiayi, Taiwan as in indicated in Fig. 5 and were constantly invited to perform by colleges, which also earned favorable comment.

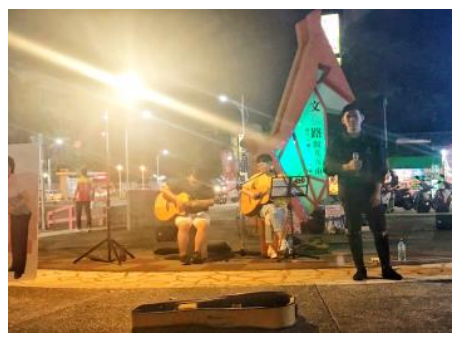

Fig. 5. Guitar club performing in Culture Park, Chiayi, Taiwan. 


\section{E. Career Performance of Student}

Bo $\mathrm{Yu}$ Chen who was a graduate taking this course fully performed unique creative work and idea in the learning process. He kept enhancing his professional skill and accumulated quite a lot of personal works and was trying to take the cases in photography, shooting, or post-production in order to be more skilled and solid in professional technique after class. After graduation, he continued to study on shooting and post-production and constantly produced good works which were recommended to the local professional work teamwork. He also unleashed his talents and continued to study and cooperate with senior professionals in the same area so as to produce excellent and outstanding performance results. He was also invited to lecture on microfilm shooting, post-production, and photography in Department of Performance Art, Private Dong Wu Senior Industrial Home Economics Vocational High School, Chiayi, Taiwan, in which his expertise was professionally recognized.

\section{CONCLUSIONS}

Our course design of Digital audio and video post-production met the expect of students. The course assessments were diverse in every aspects of performance so as to promote the student learning motive and learning outcomes. According to the feedback of student learning outcomes from students, there were very outstanding achievements in every aspect including student's affirmative of course assessment, internship of course, percentage passing rate of certification, performance of social activity, improvement of course teaching, official affirmative of teaching presentation, and post-graduation careers, so as to promote self-achievement of student and continue to grow of my dedication to teaching practice application.

\section{CONFLICT OF INTEREST}

The author declares no conflict of interest.

\section{AUTHOR CONTRIBUTIONS}

The author had approved the final version, and Rong-Wang Hsu was the sole author of this paper.

\section{REFERENCES}

[1] P. M. Wishon, K. Crabtree, and M. E. Jones, Curriculum for the Primary Years: An Integrative Approach, Upper Saddle River, NJ: Merrill, an imprint of Prentice Hall, 1998.

[2] S. C. Wortham, The Integrated Classroom: The Assessment-Curriculum Link in Early Childhood Education, Englewood Cliffs, NJ: Prentice-Hall, Inc, 1996.

[3] C. C. Hsieh, H. C. Yen, and L. Y. Kuan, "The relationships among principals'technology leadership, teaching innovations, and students' academic optimism in elementary schools," presented at International Conference on Educational Technologies \& Sustainability, Technology \& Education, New Taipei, Taiwan, 2014.

[4] C. Magno, "Standards of teacher competence on student assessment in the Philippines," The Assessment Handbook, vol. 10, pp. 41-53, 2013.

[5] C. H. Huang and C. S. Wu, "A study of the relationship a mong teachers' professional development, teachers' professional commitment and teachers' teaching effectiveness- TEPS database for example," Journal of Teacher Education and Professional Development, vol. 6, no. 2, pp. 117-140, 2013.

[6] F. Bertschy, C. Künzli, and M. Lehmann, "Teachers' competencies for the implementation of educational offers in the field of education for sustainable development," Sustainability, vol. 5, no. 12, pp. 5067-5080, 2013.

[7] K. K. Hipp, J. B. Huffman, A. M. Pankake, and D. F. Oliier, "Professional learning communities: A review of the literature," Journal of Educational Change, vol. 7, no. 4, pp. 221-258, 2008.

[8] S. M. Hord, "Professional learning communities," Journal of Staff Development, vol. 30, no. 1, pp. 40-43, 2009.

[9] C. Mitchell and L. Sackney, "Profound improvement: Building capacity for a learning community," Lisse, The Netherlands: Swets \& Zeitlinger, 2000.

[10] R. DuFour and R. Eaker, "New insights into professional learning communities at work," Bloomington: Solution Tree, 2008.

[11] C. J. Chang and Y. N. Chang, "A case study on teacher culture and development of professional learning communities in an elementary school," School Administration Bimonthly, vol. 114, pp. 252-282, 2018.

[12] S. M. Hord, "Professional learning communities: An overview," Learning Together, Leading Together: Changing School through Professional Learning Communities, NY: Teachers College Press, pp. 5-14, 2004.

[13] R. Reichsteer. (2006). Defining a professional learning community: Literature review. [Online]. Available: http://www.wcpss.net/evaluation-research/reports/2006/0605plc_lit_r eview.pdf

[14] C. Stewart, "Transforming professional development to professional learning," Journal of Adult Education, vol. 43, no.1, pp. 28-33, 2014.

[15] K. K. Hipp and J. B. Huffman, "Professional learning communities: Assessment-development-effects," presented at the International Congress for School Effectiveness and Improvement, Sydney, Australia, 2003.

[16] L. Wang, X. Wang, N. Liang, and M. Xiao, "How to make highly rational use of modern educational technologies," Intelligent Information Management, no. 2, pp. 647-651, 2010

[17] T. Kuoa, C. H. Lub, H. T. Tsaia, and Y. Y. Tseng, "User acceptance of e-learning system: A self-directed learning perspective," Journal of e-Business, vol. 10, no.4, pp. 963-988, 2008.

[18] S. Saltzberg and S. Polyson, "Distributed Learning on the world wide web," Syllabus, vol. 9, no.1, pp. 10-12, 1995.

[19] M. I. Santally and J. J. Raverdy, "The master's program in computer-mediated computer communications: A comparative study of two cohorts of students," Educational Technology Research and Development, vol. 54, no. 3, pp. 312-326, 2006.

[20] S. Alexander, "Teaching and learning on the world wide web," presented at AusWeb95 the First Australian WorldWideWeb Conference, 1995

[21] W. R. Bollentin, "Can information technology improve education," Measuring Voices, Attitudes and Perceptions, Educom Review, vol. 33, no. 1, pp. 50-54, 1998.

[22] M. McClintock, "Information systems management issues in small colleges and universities," Campus-Wide Information Systems, vol. 15, no. 3, pp. 85-90, 1998.

[23] D. Tolhurst, "Hypertext, hypermedia, multimedia defined," Educational Technology, vol. 35, no. 2, pp. 21-26, 1995.

[24] M. Wild and A. Omari, "Developing educational content for the web: Issues and ideas," presented at AusWeb96 the Second Australian WorldWideWeb Conference, 1996.

[25] A. M. Masgoret and R. C. Gardner, "Attitudes, motivation, and second language learning: A meta-analysis of studies conducted by Gardner and Associates," Language Learning, vol. 53, no. 1, pp. 123-163, 2003.

[26] K. Rubin, W. Bukowski, and J. Parker, "Peer interactions, relationships, and groups," Handbook of Child Psychology: Social, Emotional, and Personality Development, New York: Wiley, vol. 3, pp. 621-700, 1998.

[27] N. Falchikov, Learning Together: Peer Tutoring in Higher Education, London: Routledge Falmer, 2001.

[28] F. K. Jordan, "State professional standars/practices commissions or boards: A policy analysis paper," Washington: AACTE, 1988

[29] P. M. Friedman and N. Mohr, " Freedom of contract and occupational licensing 1890-1910," A Legal and Social Study, California Law Review, pp. 85-106, 1965.

[30] R. Trow, "Testing for teacher certification and licensing," Teacher Education Quarterly, vol. 14, no. 3, pp. 93-10, 1987.

[31] D. C. Smith, "Accreditation of teacher education institutions: An intereview with Richard Kunkel," Journal of Teacher Education, vol. 41, no. 4, pp. 3-6, 1990.

[32] N. A. Sprinthall, A. J. Reiman, and L. Thies-Sprinthall, "Teacher professional development," Handbook of Research on Teacher Education, New York: Macmillan, 1996. 
[33] R. M. Jaeger, "A proposal for setting a standar on the North Carolina High School Competency Test," presented at the Meeting of the North Carolina Association for Research in Education, Chapel Hill, NC, 1986.

[34] B. P. Janet, "Directory of fitness certifications," Journal of Physical Education, Recreation and Dance, pp. 73-74, 1990.

Copyright $(2020$ by the authors. This is an open access article distributed under the Creative Commons Attribution License which permits unrestricted use, distribution, and reproduction in any medium, provided the original work is properly cited ( $\underline{\text { C BY 4.0). }}$.

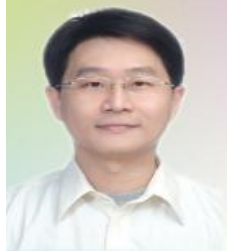

Rong-Wang Hsu was born in Kaohsiung, Taiwan. In 2007, he studied doctorate in information technology at CYUT (Chaoyang University of Technology) of science and technology in Taiwan. He graduated in 2013 with a Ph.D. in information management. His main research fields are multimedia applications and information technology. His research interests include multimedia applications, marketing management

Rong-Wang Hsu taught in the Department of Information Management of Wufeng University in Chiayi, Taiwan since 1999. He taught in the Department of Applied Digital Media in 2013. His teaching subjects focus on multimedia applications, and he is currently an assistant professor . 